\title{
Cholesterol Degradation and Production of Extracellular Cholesterol Oxidase from Bacillus pumilus W1 and Serratia marcescens W8
}

\author{
Hasina Wali, ${ }^{1,2}$ Fazal Ur Rehman, ${ }^{2}$ Aiman Umar, ${ }^{1}$ and Safia Ahmed ${ }^{1}{ }^{1}$ \\ ${ }^{1}$ Department of Microbiology, Quaid-i-Azam University, Islamabad 45320, Pakistan \\ ${ }^{2}$ Department of Microbiology, University of Balochistan, Quetta 87300, Pakistan \\ Correspondence should be addressed to Safia Ahmed; safiamrl@yahoo.com
}

Received 1 February 2019; Revised 29 March 2019; Accepted 1 April 2019; Published 28 April 2019

Academic Editor: Gjumrakch Aliev

Copyright (C) 2019 Hasina Wali et al. This is an open access article distributed under the Creative Commons Attribution License, which permits unrestricted use, distribution, and reproduction in any medium, provided the original work is properly cited.

Cholesterol is a waxy substance present in all types of the body cells. The presence of higher concentration of low density lipoprotein (LDL) is characterized by abnormal cholesterol level and is associated with cardiovascular diseases which lead to the development of atheroma in arteries known as atherosclerosis. The transformation of cholesterol by bacterial cholesterol oxidase can provide a key solution for the treatment of diseases related to cholesterol and its oxidized derivatives. Previously isolated bacteria from oil-contaminated soil were screened for cholesterol degradation. Among fourteen, five isolates were able to utilize cholesterol. Two strains Serratia marcescens W1 and Bacillus pumilus W8 using cholesterol as only carbon and energy source were selected for degradation studies. Several parameters (incubation time, substrate concentration, $\mathrm{pH}$, temperature, and different metal ions) for cholesterol decomposition by the selected bacterial strains were evaluated. Maximum cholesterol reduction was achieved on the $5^{\text {th }}$ day of incubation, $\mathrm{g} / \mathrm{L}$ of substrate concentration, $\mathrm{pH}$ 7, in the presence of $\mathrm{Mg}^{2+}$ and $\mathrm{Ca}^{2+}$ ions, and at $35^{\circ} \mathrm{C}$. Cholesterol degradation was analyzed by enzymatic colorimetric method, thin layer chromatography (TLC), and high-performance liquid chromatography (HPLC). Under optimized conditions $50 \%$ and $84 \%$ cholesterol reduction were recorded with Serratia marcescens W1 and Bacillus pumilus W8, respectively. Cholesterol oxidase activity was assayed qualitatively and quantitatively. The results revealed that Serratia marcescens W1 and Bacillus pumilus W8 have great potential for cholesterol degradation and would be regarded as a source for cholesterol oxidase $(\mathrm{CHO})$.

\section{Introduction}

Cholesterol is a steroid generally found in human and animal tissues and also in plasma lipoprotein either as free cholesterol or linked with fatty acids. It plays major role in vitamin $\mathrm{D}$ and hormones production to build healthy cells and also substances to aid digestion [1]. The level of cholesterol in the body is regulated and maintained by cholesterol synthesis and absorption, which have a reciprocal relationship, and by elimination of cholesterol into the bile. That is why, the proper evaluation of synthesis, absorption, and trafficking of cholesterol all over the body is critical to health research [2]. Several diseases emerge due to imbalance in these processes. In pathological process, cholesterol plays a major role in the development of atherosclerosis of main arteries causing cerebrovascular, peripheral, and coronary vascular diseases
[1]. Furthermore, cholesterol rich diet has strong association with prevalence of coronary heart diseases (CHD). The epidemiological studies also demonstrated a strong link between the risk of coronary heart disease and plasma cholesterol concentration [3].

The oxidation products of cholesterol are known as oxysterols, which are considered to be involved in the pathogenesis of atherosclerotic lesions; the major oxidation product of cholesterol is 7-ketocholesterol which is more atherogenic than cholesterol [4]. Both in vitro [5] and in vivo [6, 7] inflammatory effects have been shown by this oxysterol. Its cytotoxic and inflammatory effects on the cells are proven and also reported in the pathogenesis of several neurodegenerative diseases $[7,8]$, heart diseases $[6,9]$, cancer [10], and Parkinson's disease [8] as well as age-related macular degeneration $[8,11]$. 
In developed countries atherosclerosis is the leading cause of death. It develops slowly and usually asymptomatically until brittle arterial plaques rupture and causes a stroke or heart attack [12]. In the artery walls, high concentrations of oxidized lipoprotein are associated with development of atherosclerosis [13]. Macrophages and endothelial cells make efforts to remove these accumulations, but are incapable of carrying out this function. As a result, they transform into defective foam cells due to saturation with fatty material. More immune cells are attracted, due to inflammation and fibrosis which further add to instead of resolving the storage problem [14].

Many bacterial species have been reported to be involved in biodegradation of cholesterol by means of bifunctional, flavin adenine dinucleotide containing cholesterol oxidase which oxidizes the cholesterol and produces 4-cholesten-3one, with reduction of oxygen to hydrogen peroxide $[15,16]$. The degradation of cholesterol by Mycobacterium, Rhodococcus, Brevibacterium, Streptomyces, and some other Gram positive as well as Gram negative genera including Comamonas, Burkholderia, Pseudomonas, and Chromobacterium has been reported [17-22].

Significant attention has been received by cholesterol oxidase due its wider use for detection of cholesterol in food and blood samples, which has direct implication in lipid disorders including coronary heart diseases and atherosclerosis. Additionally, cholesterol oxidase is used in production of steroids [23]. Although in human body cholesterol is a vital substance, with age due to catabolic insufficiency these compounds start to accumulate, which is associated with certain age-related diseases. As the endogenous system fails to remove these compounds, the enzyme replacement therapy is an alternative therapeutic option in which microbial enzymes are used to degrade the pathogenic compounds $[24,25]$.

The present study was aimed at screening the potent cholesterol decomposing bacteria, isolated from oil-contaminated soil, and evaluating their potential for cholesterol oxidase production.

\section{Material and Methods}

2.1. Chemicals. The substrate cholesterol was purchased from VWR Life Science AMRESCO ${ }^{\circledR}$ (Ultra-Pure Grade). In all experiments M9 salt medium was used as growth medium. The composition of growth medium was $15 \mathrm{~g} \mathrm{KH}_{2} \mathrm{PO}_{4}, 64$ $\mathrm{g} \mathrm{Na}_{2} \mathrm{HPO}_{4} .7 \mathrm{H}_{2} \mathrm{O}$, $5.0 \mathrm{~g} \mathrm{NH}_{4} \mathrm{Cl}, 2.5 \mathrm{~g} \mathrm{NaCl}, 2 \mathrm{~mL}$ of $1 \mathrm{M}$ $\mathrm{MgSO}_{4}$, and $0.1 \mathrm{~mL}$ of $1 \mathrm{M} \mathrm{CaCl}_{2}$ in $1000 \mathrm{~mL}$ of distilled water.

2.2. Screening of Cholesterol Degrading Bacteria. Several bacterial isolates from oil-contaminated soil were screened on M9 salt agar plates containing $0.1 \%$ cholesterol as the only carbon source. Cholesterol plates were streaked with cultures and incubated in an incubator at $37^{\circ} \mathrm{C}$ for 7 days. The potentiality of bacteria to utilize cholesterol was evaluated via the growth of bacteria on these plates.

2.3. Optimization Studies. To optimize several degradation parameters, throughout the study shake flask fermentation experiments were carried out with $100 \mathrm{~mL}$ of fermentation broth (M9 medium) in conical flasks $(250 \mathrm{~mL})$ containing $0.1 \%$ cholesterol and inoculated with $2 \%(\mathrm{v} / \mathrm{v})$ bacterial culture and incubated at $30^{\circ} \mathrm{C}$. Different factors affecting the degradation of cholesterol were studied, such as incubation time (1 to 6 days), incubation temperature $\left(25\right.$ to $\left.45^{\circ} \mathrm{C}\right), \mathrm{pH}$ values ( $\mathrm{pH} 3$ to 9), different metal ions $\left(\mathrm{MgSO}_{4}, \mathrm{CaCl}_{2}, \mathrm{BaCl}_{2}\right.$, $\left.\mathrm{CoCl}_{2}\right)$, and different substrate concentrations (0.5 to $\left.2 \mathrm{~g} / \mathrm{L}\right)$.

2.4. Analysis of Cholesterol Degradation. Enzymatic colorimetric cholesterol oxidase peroxidase method was used to calculate the cholesterol degradation [26]. Growth was monitored at $600 \mathrm{~nm}$ using spectrophotometer. Cholesterol estimation kit (Merck) was used in order to perform cholesterol assay. All the reagents were mixed well according to manufacturer's instructions. In the reaction mixture $10 \mu \mathrm{L}$ of cell free supernatant (CFS) was added, mixed by inversion, and then incubated at $37^{\circ} \mathrm{C}$ for 10 minutes. The absorbance of test and standard was checked against the blank at $\lambda 505$ $\mathrm{nm}$, and concentration of cholesterol was determined by the following formula.

$$
\begin{aligned}
& \text { Cholesterol }[\mathrm{mg} / \mathrm{dL}] \\
& =\frac{\text { Absorbance of test }}{\text { Absorbance of standard }} \\
& \quad \times \text { Conc. of standard }[\mathrm{mg} / \mathrm{dL}]
\end{aligned}
$$

Further the percent cholesterol degradation was calculated from the cholesterol concentrations at the start of the experiment and after certain time intervals. The culture supernatant of the cholesterol degradation experiments was extracted with a mixture of hexane/isopropanol (3:2), dried and redissolved in hexane to be analyzed by TLC and HPLC.

2.4.1. TLC Analysis. To quantify and visualize the cholesterol degrading potency of each bacterial strain, extracted samples were applied on the silica gel plates. Different dilutions of cholesterol $(0.1-1.0 \mathrm{mg} / \mathrm{mL})$ were applied on the same silica plate to compare the spot intensity. Silica plates were set in a chromatography tank containing hexane/ethyl acetate (1:1). The dried plates were sprayed with $15 \%$ phosphomolybdic acid, and spots of varying intensity were developed.

2.4.2. HPLC Analysis. To verify the cholesterol degradation, extracted sample was redissolved in hexane and filtered, and $20 \mu \mathrm{L}$ was analyzed by reverse phase HPLC using Waters HPLC system with UV detector and C18 column, at $\lambda 210 \mathrm{~nm}$ and hexane/acetonitrile (96:4) was used as mobile phase with a flow rate of $0.72 \mathrm{~mL} / \mathrm{min}$.

\subsection{Qualitative Analysis of Cholesterol Oxidase}

2.5.1. Colony Staining Method. Colony staining method was performed on the selected strains to confirm their cholesterol oxidase production. Filter discs were immersed into a mixture containing $6 \%$ phenol, $1.7 \%$ 4-aminoantipyrine, $0.5 \%$ cholesterol, and $3 \mathrm{U} / \mathrm{mL}$ horse radish peroxidase (HRP) in $100 \mathrm{mM}$ potassium phosphate buffer ( $\mathrm{pH}$ 7.0). After that, filter discs were placed on fresh colonies of $B$. pumilus 
W8 and S. marcescens W1 and incubated at $37^{\circ} \mathrm{C}$ for 24 hrs. The appearance of red color is the confirmation of cholesterol oxidase production because of the formation of quinoneimine dye [27].

2.5.2. Cholesterol Oxidase Indicator Plates. Cholesterol oxidase producing $B$. pumilus W8 and $S$. marcescens W1 was selected on indicator plates containing $1.0 \mathrm{~g} / \mathrm{L}$ Triton X$100,1.0 \mathrm{~g} / \mathrm{L}$ cholesterol, $0.1 \mathrm{~g} / \mathrm{L}$ o-dianisidine, and $1 \mathrm{U} / \mathrm{mL}$ horse radish peroxidase of agar medium. On these plates, cultures were streaked and incubated at $37^{\circ} \mathrm{C}$. Cholesterol oxidase from bacteria converts the cholesterol into hydrogen peroxide $\left(\mathrm{H}_{2} \mathrm{O}_{2}\right)$, changes the medium color to intense brown due to formation of azo compound, and was taken as positive result.

\subsection{Quantitative Analysis of Cholesterol Oxidase}

2.6.1. Enzyme Assay Method I. The activity of cholesterol oxidase was measured by generation of $\mathrm{H}_{2} \mathrm{O}_{2}$ [28]. The assay mixture (total $1 \mathrm{~mL}$ ) consisted of $87 \mathrm{mM}$ potassium phosphate buffer, $0.89 \mathrm{mM}$ cholesterol, $64 \mathrm{mM}$ sodium cholate, $1.4 \mathrm{mM}$ 4-aminoantipyrine, $21 \mathrm{mM}$ phenol, $0.34 \%$ tween 80 , and horse radish peroxidase $5 \mathrm{U} / \mathrm{mL}$. The reaction mixture was incubated with $100 \mu \mathrm{L}$ of enzyme at $35^{\circ} \mathrm{C}$ for 5 minutes, and the formation of quinoneimine dye was tracked by checking the absorbance at $\lambda 500 \mathrm{~nm}$.

The activity of enzyme was calculated according to following formula:

$$
\begin{aligned}
\text { Unit } / \mathrm{mL}= & \frac{\Delta \mathrm{OD} / \mathrm{min}(\Delta \mathrm{OD} \text { test }-\Delta \mathrm{OD} \text { blank })}{13.78 \times \mathrm{Vs}} \\
& \times \mathrm{Vt} \times \mathrm{df}
\end{aligned}
$$

where $\mathrm{Vt}$ is the total volume $(1 \mathrm{~mL})$ of assay, 13.78 is the millimolar extinction coefficient of quinoneimine dye, $\mathrm{df}$ is the dilution factor, and $\mathrm{Vs}$ is the enzyme volume $(0.1 \mathrm{~mL})$ used in assay.

2.6.2. Enzyme Assay Method II. Enzyme assay was also accomplished by measuring the degradation of cholesterol into cholest-4-en-3-one. Cholesterol solution (1 mL) was mixed with $1 \mathrm{~mL}$ of phosphate buffer. Spectrophotometer was calibrated against the same buffer blank, then $0.1 \mathrm{~mL}$ of crude enzyme was added and incubated in a shaker incubator for 1 minute at $35^{\circ} \mathrm{C}$, then $20 \mu \mathrm{L}$ of triton $\mathrm{X}-100$ was added in order to stop the reaction, and enzyme activity was measured at $\lambda 240 \mathrm{~nm}$ and calculated according to the following formula:

$$
\begin{aligned}
& \text { Enzyme activity (unit } / \mathrm{mL} \text { ) } \\
& =\frac{\Delta \mathrm{OD} \times \text { Total volume } \times 0.082}{\text { Volume of enzyme taken }}
\end{aligned}
$$

2.7. Protein Estimation. Method of Lowry et al. [29] was used for estimation of total protein content. Bovine serum albumin was taken as standard.

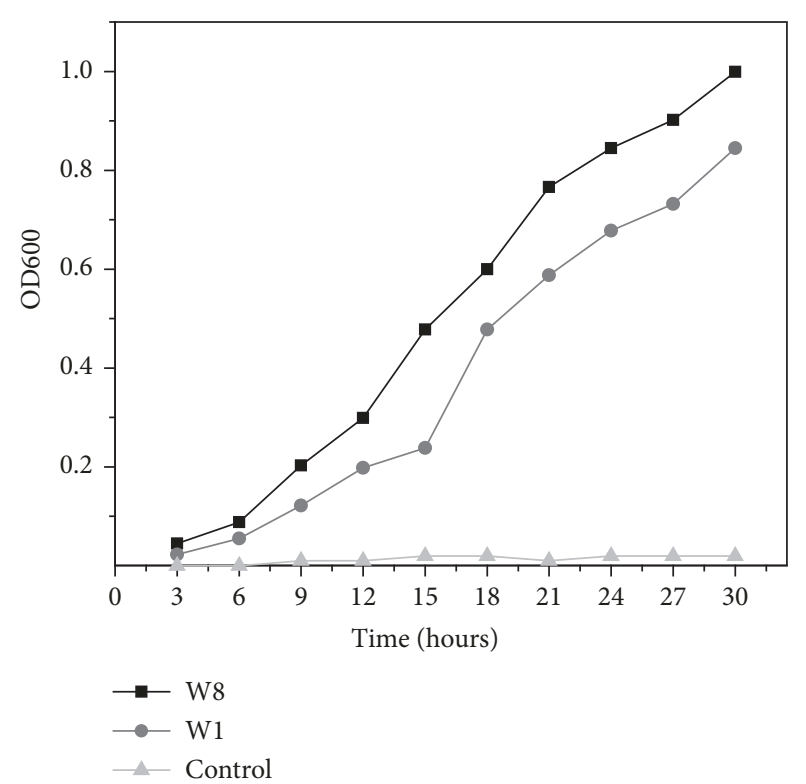

FIgURE 1: Growth of the Bacillus pumilus W8 and Serratia marcescens W1 in M9 media with cholesterol as carbon source.

2.8. Purification of Enzyme. The extracellular enzyme from the fermentation broth of the selected strains was purified by solvent precipitation using acetone. Precipitation was performed by using different broth to acetone ratios such as 1:1, 1:2, 1:3, and 1:4. In phosphate buffer the precipitated enzyme was resuspended and kept at $4^{\circ} \mathrm{C}[30]$.

\section{Results}

3.1. Screening of Isolated Microorganisms. Several bacterial strains were checked for their growth on M9 salt media. Some bacterial isolates utilized cholesterol and grown well on M9 cholesterol agar media. On the basis of maximum growth, B. pumilus W8 and S. marcescens W1 were selected for optimization studies and cholesterol oxidase production.

3.2. Degradation of Cholesterol by B. pumilus W8 and S. marcescens $W 1$. The selected bacterial isolates were inoculated in M9 broth and their growth was determined by increase in $\mathrm{OD}_{600}$. The gradual increase in the growth was observed and the absorption at $600 \mathrm{~nm}$ reached 0.845 and 0.999 for $S$. marcescens W1 and B. pumilus W8, respectively, in 30 hours (Figure 1).

\subsection{Optimization of Process Variables}

3.3.1. Incubation Period. As shown in Figure 2(a), the highest degradation of cholesterol was attained on the $5^{\text {th }}$ day of incubation, by both the isolates. Generally, at any incubation time the decomposition of cholesterol by B. pumilus W8 was significantly higher as compared to $S$. marcescens W1.

3.3.2. Substrate Concentration. Both the isolates S. marcescens W1 and B. pumilus W8 showed increased cholesterol degradation with increasing concentration of cholesterol from 0.5 

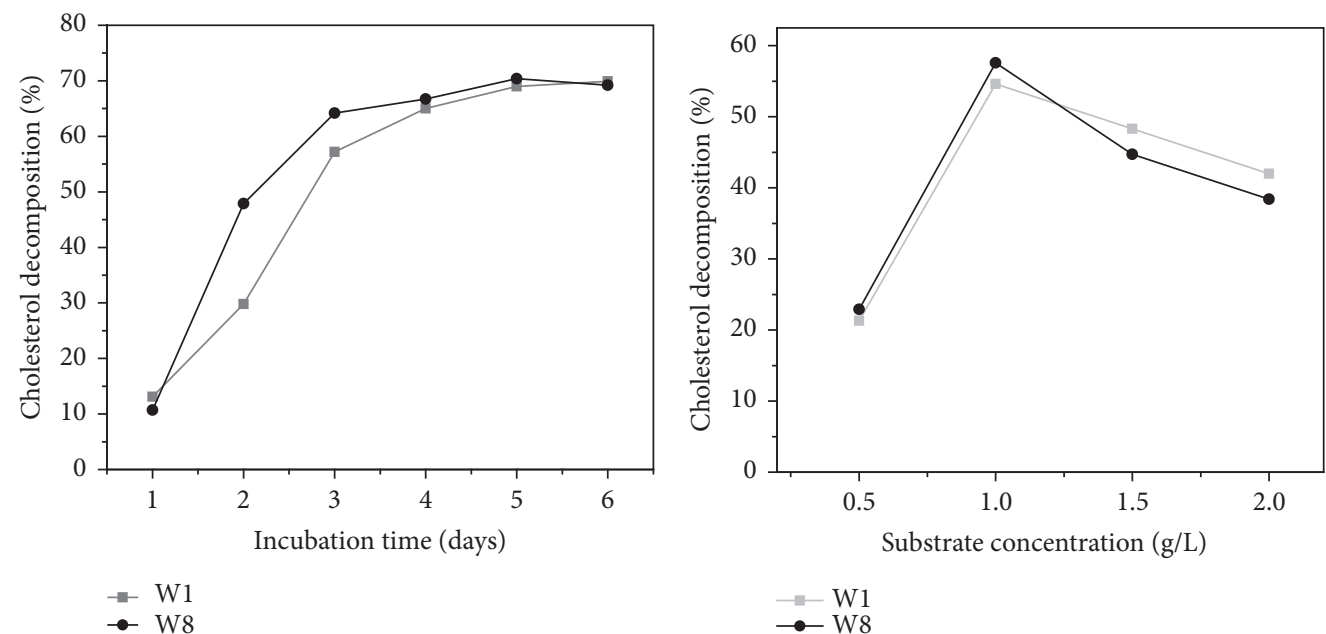

(a)

(b)
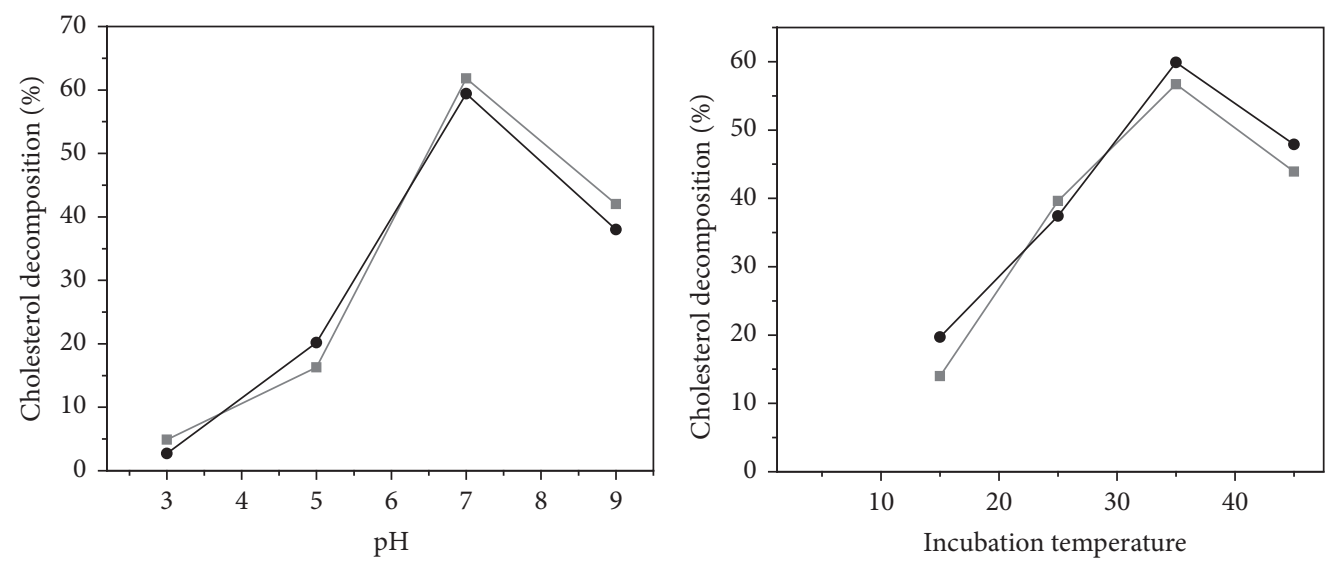

$-\mathrm{W} 1$

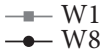

(c)

(d)

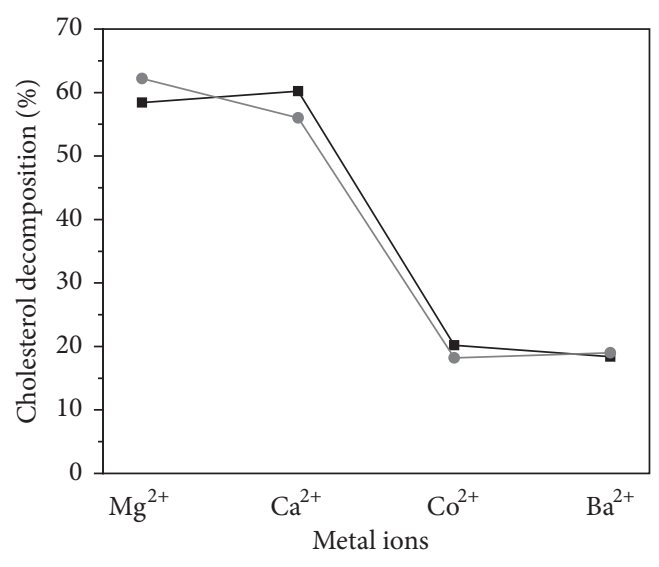

$-\mathrm{W} 8$

$\rightarrow$ W1

(e)

FIGURE 2: Effect of different parameters on degradation of cholesterol in M9 medium: (a) incubation time; (b) cholesterol concentration; (c) $\mathrm{pH}$; (d) temperature; and (e) metal ions. 


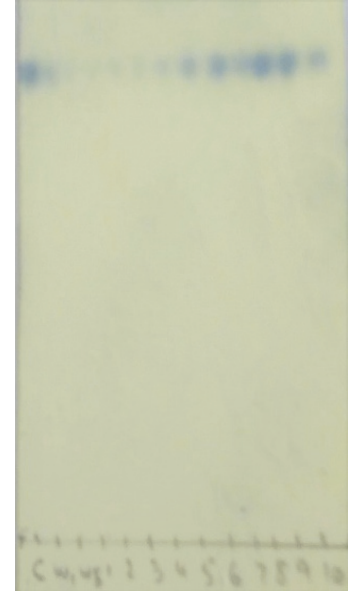

FIGURE 3: TLC of cholesterol degradation by Serratia marcescens W1 and Bacillus pumilus W8 and its comparison with control (C) and with different concentration of cholesterol (0.1-1.0 g/L).

up to $1.0 \mathrm{~g} / \mathrm{L}$, while further increase in concentration of cholesterol reduced the degradation (Figure 2(b)). Maximum degradation of cholesterol (54.6\% and 57.6\%) was observed with Serratia marcescens W1 and Bacillus pumilus W8 at a concentration of $1.0 \mathrm{~g} / \mathrm{L}$.

3.3.3. $\mathrm{pH}$. The most favorable $\mathrm{pH}$ for decomposition of cholesterol by $S$. marcescens W1 and B. pumilus W8 was $\mathrm{pH}$ 7.0 (Figure 2(c)). The activities of both the isolates decreased towards alkaline and acidic sides. The cholesterol decomposing activity was better at moderate alkaline $\mathrm{pH}(9.0)$ in comparison with acidic (5.0). At the extremely acidic $\mathrm{pH}(\mathrm{pH}$ 3.0) both $S$. marcescens W1 and B. pumilus W8 did not grow well.

3.3.4. Incubation Temperature. With increasing temperature from 15 to $35^{\circ} \mathrm{C}$, the cholesterol decomposition significantly increased, and with further increase in temperature, the cholesterol decomposing activity decreased (Figure 2(d)).

3.3.5. Metal Ions. $\mathrm{Mg}^{+2}$ and $\mathrm{Ca}^{+2}$ were the most appropriate metallic ions for cholesterol decomposing activity. The maximum reduction was recorded with $\mathrm{MgSO}_{4}$ and $\mathrm{CaCl}_{2}$ by both Bacillus pumilus W8 and Serratia marcescens $\mathrm{W} 1 . \mathrm{BaCl}_{2}$ and $\mathrm{CoCl}_{2}$ also showed positive effect on cholesterol degradation but less as compared to $\mathrm{Mg}^{+2}$ and $\mathrm{Ca}^{+2}$ for both the tested isolates (Figure 2(e)).

TLC analysis was carried out in order to determine whether cholesterol level decreased and number of metabolites produced during the growth of bacterial strains. The transformation extracts showed single spot with low intensity, indicating the utilization of cholesterol with no accumulation of metabolites (Figure 3).

Degradation of cholesterol was observed with Serratia marcescens W1 and Bacillus pumilus W8 on the basis of HPLC analysis (Figures 4(a), 4(b), and 4(c)). The strains W1 and W8 cleared $50 \%$ and $84 \%$ of cholesterol, respectively, after four days of incubation (Figure $4(\mathrm{~d})$ ).
Cholesterol oxidase production was assessed by quantitative and qualitative method. For qualitative analysis, cholesterol oxidase indicator plate sssay and colony staining method were carried out. In colony staining cholesterol oxidase was confirmed by formation of red color (Figures 5 and 6).

While in the indicator plate assay the development of azo component turns the medium into intense brown due to the presence of $\mathrm{H}_{2} \mathrm{O}_{2}$ produced by reaction of cholesterol oxidase (Figure 6).

For quantitative analysis cholesterol oxidase was purified by solvent extraction at acetone to broth (1:1) ratio. The activity of cholesterol oxidase isolated from culture supernatant of B. pumilus W8 and S. marcescens W1 was recorded to be 1.64 $\mathrm{U} / \mathrm{mL}$ and $1.47 \mathrm{U} / \mathrm{mL}$ as compared to crude which was 1.26 $\mathrm{U} / \mathrm{mL}$ and $1.03 \mathrm{U} / \mathrm{mL}$, respectively.

\section{Discussion}

Intracellular accumulations of recalcitrant substances impair the cell viability and function, leading to development of macular degeneration, atherosclerosis, and neurodegenerative diseases [31]. Accumulation of cholesterol is linked to some of the diseases including stroke, coronary heart disease, peripheral vascular disease, high blood pressure, and diabetes. Elevated serum cholesterol is usually regarded as a risk factor for other diseases depending on the type of blood vessels which are blocked or narrowed [32].

Oxidized sterols preferentially generated by the oxidation of cholesterol. 7-Ketocholesterol is the oxidized derivative of cholesterol formed by the free radical attack on carbon 7 of the cholesterol. Elevated concentrations of the oxysterol are linked with decreased cell viability, disruption of cellular homeostasis, and increased cell death [33].

From diverse habitat, several bacteria and their enzymes have been reported to have the ability to degrade cholesterol and 7-ketocholesterol. The degradation of these compounds is initiated by most of these species with the same reaction mechanism as cholesterol oxidase [34].

In the present study bacteria were isolated from oilcontaminated sites and showed the activity for cholesterol degradation and cholesterol oxidase production. Two of the isolates, B. pumilus W8 and S. marcescens W1, were showing maximum activity for cholesterol degradation. Saranya et al. [35]. isolated the Bacillus sp. from the oil and soap industrial wastes, with a potential to degrade the cholesterol. Several species of Bacillus and Serratia are reported to have cholesterol degrading ability $[27,36]$.

Regarding the effect of incubation time, the maximum cholesterol degrading activity was detected after four days of incubation. The incubation time varies in different microorganisms for cholesterol decomposition. The maximum cholesterol utilization by Bacillus cereus was attained after 24 hrs incubation [27], while the others reported 3-7 days for the maximum degradation of cholesterol by most of Rhodococcus strains [37].

Some microorganisms effectively degraded the cholesterol based on the temperature. The strains in the present study, W1 and W8, degraded maximum cholesterol at 


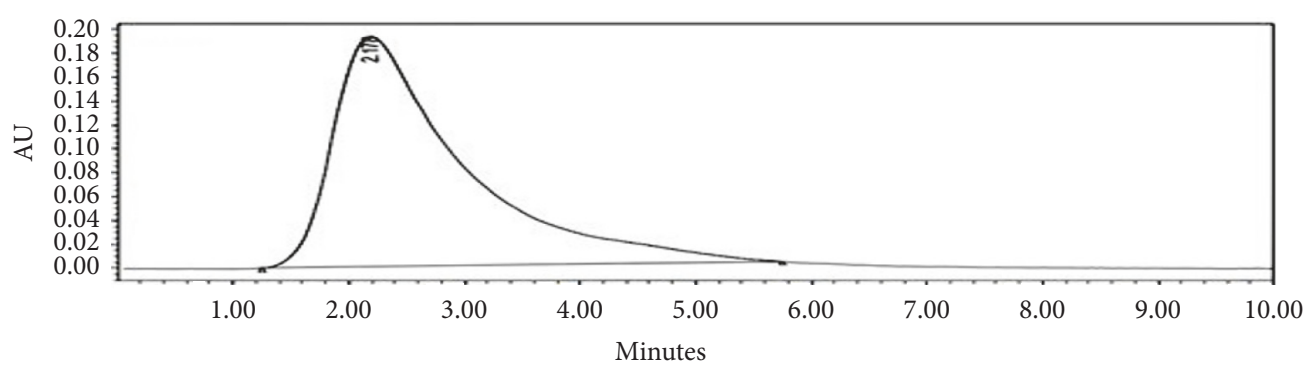

(a)

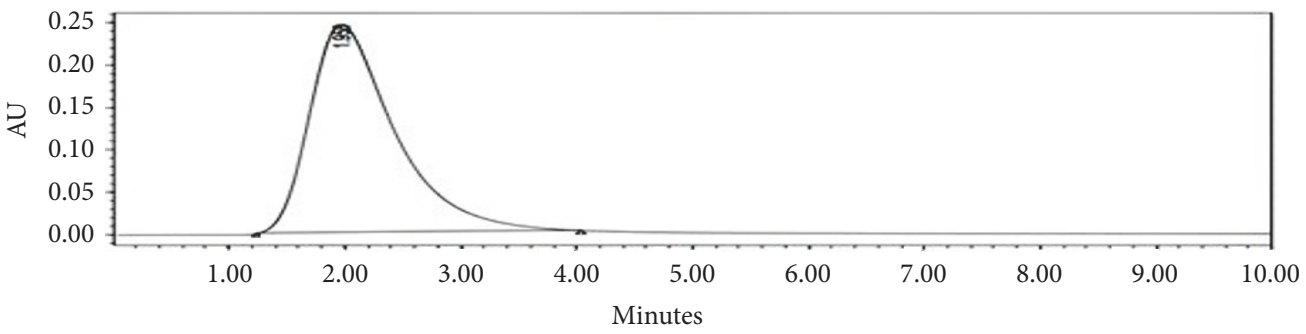

(b)

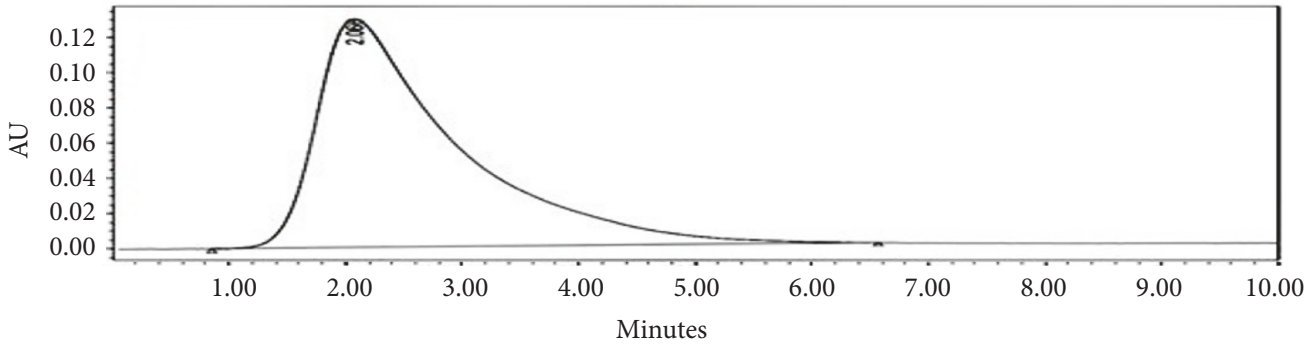

(c)

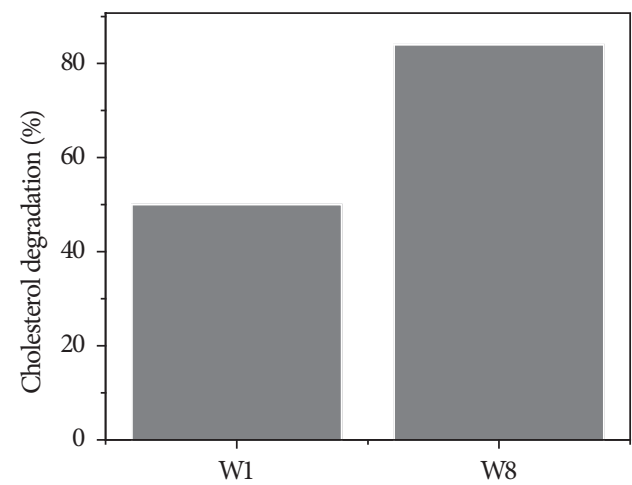

(d)

FIGURE 4: HPLC analysis of cholesterol degradation: (a) zero (0) time; (b) Serratia marcescens W1 sample after 4 days; (c) Bacillus pumilus W8 sample after days; (d) \% degradation.

$35^{\circ} \mathrm{C}$. During the optimization studies of Bacillus subtilis strain, KAVK3 degraded maximum cholesterol at $35^{\circ} \mathrm{C}$ [38].

The maximum cholesterol degradation by both the tested isolates was attained at $\mathrm{pH}$ 7.0. The cholesterol decomposing activity was steadily decreased with $\mathrm{pH}$ shift away from the optimum. Similarly, it has been reported previously that $\mathrm{pH}$ 7.0 and 6.5 are the optimum $\mathrm{pH}$ for cholesterol degradation and cholesterol oxidase production by Bacillus sp. [35, 38].
In the current work cholesterol was used as the only carbon source, and its varying concentrations influence the degradation. The maximum degradation was achieved at concentration of $1.0 \mathrm{~g} / \mathrm{L}$. However, on increasing the cholesterol concentration, the degrading activity by the selected isolates significantly decreased. Ouf et al. [39] reported similar results; that is, the low concentrations were degraded more rapidly than higher concentrations of cholesterol by Streptomyces. Similarly optimum cholesterol concentration 


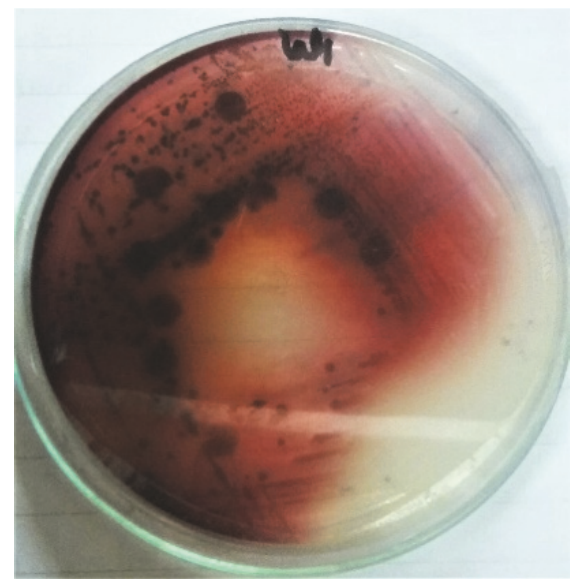

(a)

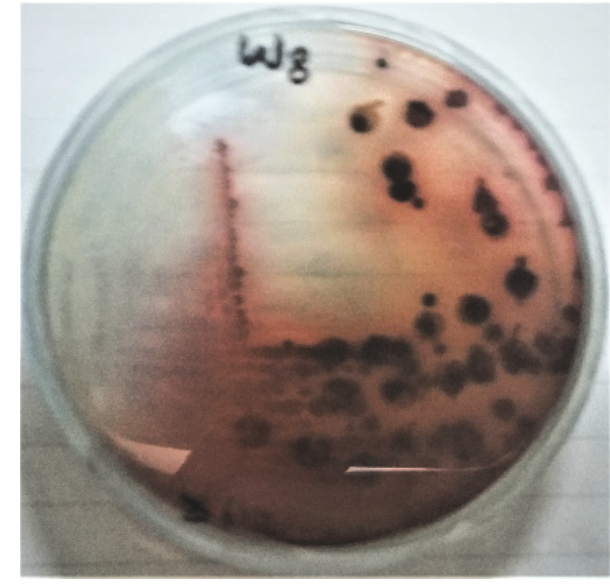

(b)

FIGURE 5: Development of red color in colony staining method due to cholesterol oxidase production: (a) Serratia marcescens W1, (b) Bacillus pumilus W8.

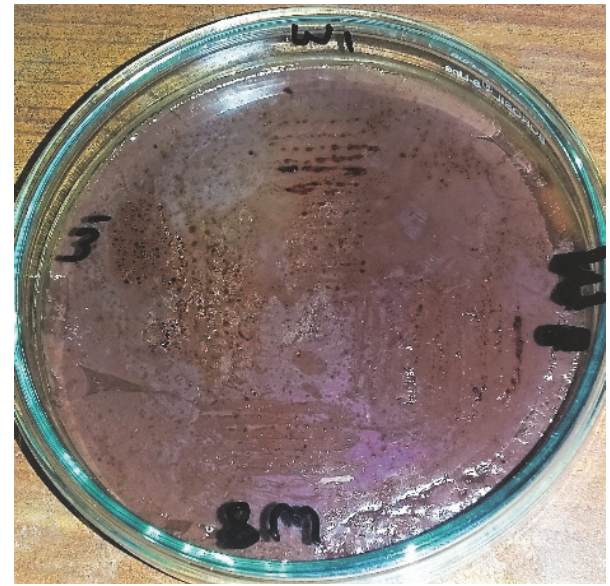

Figure 6: Growth of Serratia marcescens W1 and Bacillus pumilus W8 on cholesterol oxidase indicator plate.

$(1 \mathrm{mg} / \mathrm{mL})$ for degradation by Bacillus cereus was reported by Kuppusamay and Kumar [27].

For cholesterol degradation the most suitable metallic ions for B. pumilus W8 and S. marcescens W1 were $\mathrm{MgSO}_{4}$ and $\mathrm{CaCl}_{2}$, whereas $\mathrm{BaCl}_{2}$ and $\mathrm{CoCl}_{2}$ induced low activity for both the tested isolates. These findings are in agreement with Ouf et al. [39] who found that the most suitable ions for cholesterol degradation were $\mathrm{MgSO}_{4}$ followed by $\mathrm{CaCl}_{2}$ for treated and untreated $S$. fradiae bacteria, while for the enzymes recovered from Bacillus cereus and Pseudonocardia compacta, the most stimulatory ion was $\mathrm{MgSO}_{4}$ followed by $\mathrm{ZnSO}_{4}[27,40]$.

Based on HPLC result, $50 \%$ and $84 \%$ cholesterol reduction were achieved by S. marcescens $\mathrm{W} 1$ and B. pumilus W8, respectively. There was also no other peak present after the degradation in the tested samples indicating their complete degradation (Figures $4(\mathrm{~b})$ and $4(\mathrm{c})$ ). The degrading activity of the tested isolates was mostly because of production of extracellular cholesterol oxidase (CHO). In catabolic pathway of cholesterol, many microorganisms produce the cholesterol oxidase as an initial enzyme. The isolates tested in the present study also showed cholesterol oxidase activities in both qualitative and quantitative assays.

We have also tested Bacillus pumilus W8 and Serratia marcescens W1 for degradation of 7-ketocholesterol, and significant reduction was achieved (unpublished data).

\section{Conclusion}

The present study showed that the cholesterol degrading microorganisms from the oil-contaminated soil are endowed with the capability to degrade the cholesterol and are good source for cholesterol oxidase that can be exploited for potential biomedical, industrial, environmental, and industrial applications. Overall, these findings suggest that the biodegradation processes may control the levels of cholesterol. As cholesterol and its oxidized derivatives are associated with a number of aging diseases, its removal by exogenous catabolic enzymes can reverse the disease conditions.

\section{Data Availability}

The data used to support the findings of this study are available from the corresponding author upon request.

\section{Conflicts of Interest}

The authors declare that they have no conflicts of interest.

\section{Acknowledgments}

The authors acknowledge the Higher Education Commission, Pakistan, for providing financial support for this study. 


\section{Supplementary Materials}

Graphical abstract describing the degradation of cholesterol by bacterial isolates. (Supplementary Materials)

\section{References}

[1] D. Steinberg, "Thematic review series: the pathogenesis of atherosclerosis. an interpretive history of the cholesterol controversy, part V: the discovery of the statins and the end of the controversy," Journal of Lipid Research, vol. 47, no. 7, pp. 13391351, 2006.

[2] R. S. Blumenthal, "Statins: effective antiatherosclerotic therapy," American Heart Journal, vol. 139, no. 4, pp. 577-583, 2000.

[3] Z.-Y. Chen, R. Jiao, and Y. M. Ka, "Cholesterol-lowering nutraceuticals and functional foods," Journal of Agricultural and Food Chemistry, vol. 56, no. 19, pp. 8761-8773, 2008.

[4] G. Leonarduzzi, B. Sottero, and G. Poli, "Oxidized products of cholesterol: Dietary and metabolic origin, and proatherosclerotic effects," The Journal of Nutritional Biochemistry, vol. 13, no. 12, pp. 700-710, 2002.

[5] J. Amaral, J. W. Lee, J. Chou, M. M. Campos, and I. R. Rodríguez, "7-Ketocholesterol induces inflammation and angiogenesis in vivo: a novel rat model," PloS One, vol. 8, no. 2, article e56099, 2013.

[6] A. J. Brown and W. Jessup, "Oxysterols and atherosclerosis," Atherosclerosis, vol. 142, no. 1, pp. 1-28, 1999.

[7] A. Vejux and G. Lizard, "Cytotoxic effects of oxysterols associated with human diseases: induction of cell death (apoptosis and/or oncosis), oxidative and inflammatory activities, and phospholipidosis," Molecular Aspects of Medicine, vol. 30, no. 3, pp. 153-170, 2009.

[8] G. Poli, F. Biasi, and G. Leonarduzzi, "Oxysterols in the pathogenesis of major chronic diseases," Redox Biology, vol. 1, no. 1, pp. 125-130, 2013.

[9] D. M. van Reyk, A. J. Brown, L. M. Hult'en, R. T. Dean, and W. Jessup, "Oxysterols in biological systems: sources, metabolism and pathophysiological relevance," Redox Report, vol. 11, no. 6, pp. 255-262, 2006.

[10] S.-F. Wang, Y.-C. Chou, N. Mazumder et al., "7-Ketocholesterol induces P-glycoprotein through $\mathrm{PI} 3 \mathrm{~K} / \mathrm{mTOR}$ signaling in hepatoma cells," Biochemical Pharmacology, vol. 86, no. 4, pp. 548560, 2013.

[11] I. R. Rodríguez and I. M. Larrayoz, "Cholesterol oxidation in the retina: implications of 7-ketocholesterol formation in chronic inflammation and age-related macular degeneration," Journal of Lipid Research, 2010.

[12] J. Willeit and S. Kiechl, "Biology of arterial atheroma," Cerebrovascular Disease, vol. 10, suppl 5, pp. 1-8, 2000.

[13] J. Schloendorn, T. Webb, K. Kemmish et al., "Medical bioremediation: a concept moving toward reality," Rejuvenation Research, vol. 12, no. 6, pp. 411-419, 2009.

[14] A. J. Lusis, "Atherosclerosis," Nature, vol. 407, no. 6801, pp. $233-$ 241, 2000.

[15] H. E. Lashgarian, S. Jahanbakhsh, and K. Shahzamani, "Molecular identification of cholesterol oxidase enzyme producing Streptomyces bacteria in soil of Lorestan Province Iran," International Journal of Medical Research and Health Science, vol. 11, pp. 54-62, 2016.

[16] I. K. Sakodinskaya and A. D. Ryabov, "Crown ether activates cholesterol oxidase in low water media," Biotechnology Letters, vol. 22, no. 2, pp. 173-176, 2000.
[17] N. Doukyu, "Characteristics and biotechnological applications of microbial cholesterol oxidases," Applied Microbiology and Biotechnology, vol. 83, no. 5, pp. 825-837, 2009.

[18] L. F. De Las Heras, E. G. Fernández, J. M. N. Llorens, J. Perera, and O. Drzyzga, "Morphological, physiological, and molecular characterization of a newly isolated steroid-degrading actinomycete, identified as Rhodococcus ruber strain Chol-4," Current Microbiology, vol. 59, no. 5, pp. 548-553, 2009.

[19] J. Kreit and N. S. Sampson, "Cholesterol oxidase: physiological functions,” FEBS Journal, vol. 276, no. 23, pp. 6844-6856, 2009.

[20] L. Pollegioni, L. Piubelli, and G. Molla, "Cholesterol oxidase: biotechnological applications," FEBS Journal, vol. 276, no. 23, pp. 6857-6870, 2009.

[21] R. Van Der Geize, K. Yam, T. Heuser et al., "A gene cluster encoding cholesterol catabolism in a soil actinomycete provides insight into Mycobacterium tuberculosis survival in macrophages," Proceedings of the National Acadamy of Sciences of the United States of America, vol. 104, no. 6, pp. 1947-1952, 2007.

[22] A. Vrielink and S. Ghisla, "Cholesterol oxidase: biochemistry and structural features," FEBS Journal, vol. 276, no. 23, pp. 6826$6843,2009$.

[23] L. Kumari and S. S. Kanwar, "Cholesterol oxidase and its applications," Advances in Microbiology, vol. 2, no. 2, article 49, 2012.

[24] J. M. Mathieu, J. Schloendorn, B. E. Rittmann, and P. J. J. Alvarez, "Medical bioremediation of age-related diseases," Microbial Cell Factories, vol. 8, no. 1, article 21, 2009.

[25] M. F. Linton, P. G. Yancey, S. S. Davies et al., "The role of lipids and lipoproteins in atherosclerosis," in Endotext [Internet], MDText. com, Inc., 2019.

[26] N. S. Kulkarni, A. P. Lokhande, R. R. Pachori, P. N. Agrawal, and J. M. Dalal, "Screening of the cholesterol degrading bacteria from cows milk," Research in Microbiol Biotechnology, vol. 1, no. 3, pp. 92-94, 2013.

[27] A. Kuppusamy and K. V. Kumar, "Optimization of cholesterol oxidase production and 16S rRNA partial sequence of Bacillus cereus strain KAVK4 isolated from butter," Journal of Applied Pharmaceutical Science, vol. 6, no. 7, pp. 61-66, 2016.

[28] K. Wu, W. Li, J. Song, and T. Li, "Production, purification, and identification of cholest-4-en-3-one produced by cholesterol oxidase from Rhodococcus sp. in aqueous/organic biphasic system," Biochemistry Insights, vol. 8, article BCI-S21580, 2015.

[29] O. H. Lowry, N. J. Rosebrough, A. L. Farr, and R. J. Randall, "Protein measurement with the Folin phenol reagent," Journal of Biological Chemistry, vol. 193, no. 1, pp. 265-275, 1951.

[30] A. D. Bholay, D. J. Gadekar, S. K. Sawant, and S. M. Sonawane, "Original research article bacterial extracellular cholesterol oxidase and its pharmaceutical perspectives," International Journal of Current Microbiology and Applied Sciences, vol. 2, no. 3, pp. 19-28, 2013.

[31] B. E. Rittmann and J. Schloendorn, "Engineering away lysosomal junk: medical bioremediation," Rejuvenation Research, vol. 10, no. 3, pp. 359-365, 2007.

[32] J. Pekkanen, S. Linn, G. Heiss et al., “Ten-year mortality from cardiovascular disease in relation to cholesterol level among men with and without preexisting cardiovascular disease," The New England Journal of Medicine, vol. 322, no. 24, pp. 1700-1707, 1990.

[33] F. Brahmi, A. Vejux, R. Sghaier et al., "Prevention of 7ketocholesterol-induced side effects by natural compounds," Critical Reviews in Food Ncience and Nutrition, pp. 1-20, 2018. 
[34] S. Ghosh and S. K. Khare, "Biodegradation of cytotoxic 7Ketocholesterol by Pseudomonas aeruginosa PseA," Bioresource Technology, vol. 213, pp. 44-49, 2016.

[35] S. Saranya, S. Shekinah, T. Rajagopal, J. Vijayakumar, and P. Ponmanickam, "Isolation and characterization of cholesterol degrading bacteria from soap and vegetable oil industrial waste," Indian Journal of Biochemistry and Biophysics, vol. 13, no. 4, pp. 508-513, 2014.

[36] K. Arima, M. Nagasawa, M. Bae, and G. Tamura, "Microbial transformation of sterols: Part I. Decomposition of cholesterol by microorganisms Part II. Cleavage of sterol side chains by microorganisms," Agricultural and Biological Chemistry, vol. 33, no. 11, pp. 1636-1650, 1969.

[37] K. Watanabe, H. Shimizu, H. Aihara, R. Nakamura, K.-I. Suzuki, and K. Komagata, "Isolation and identification of cholesteroldegrading rhodococcus strains from food of animal origin and their cholesterol oxidase activities," The Journal of General and Applied Microbiology, vol. 32, no. 2, pp. 137-147, 1986.

[38] V. Kokila and K. Amutha, "Cholesterol degrading potentiality of the bacterial isolates from Ghee," International Journal of Pharmaceutical Sciences Review and Research, vol. 39, no. 2, pp. 255-259, 2016.

[39] S. A. Ouf, A. Q. Alsarrani, A. A. Al-Adly, M. K. Ibrahim, and A. A. H. Mohamed, "Evaluation of low-intensity laser radiation on stimulating the cholesterol degrading activity of Streptomyces fradiae. Part II: optimization of environmental and nutritional factors," Journal of Taibah University for Science, vol. 6, no. 1, pp. 19-27, 2012.

[40] A. A. Sabry, Decomposition of Cholesterol by Some Organisms Isolated from Certain Egyption Soils, Department Al Azhar University, Cairo, Egypt, 1994. 


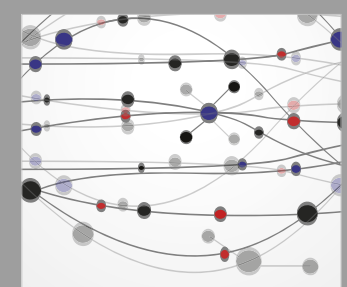

The Scientific World Journal
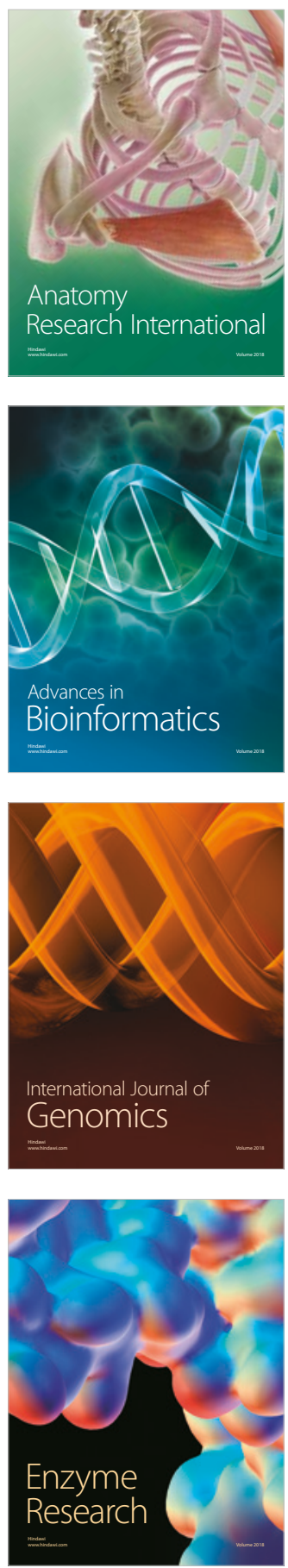
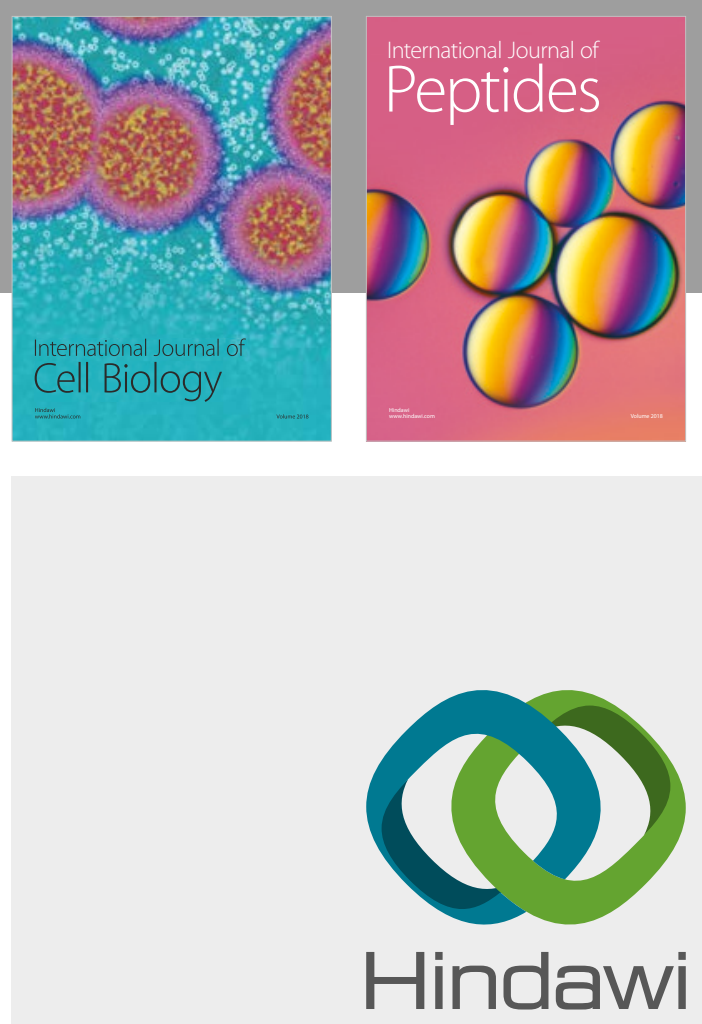

Submit your manuscripts at

www.hindawi.com
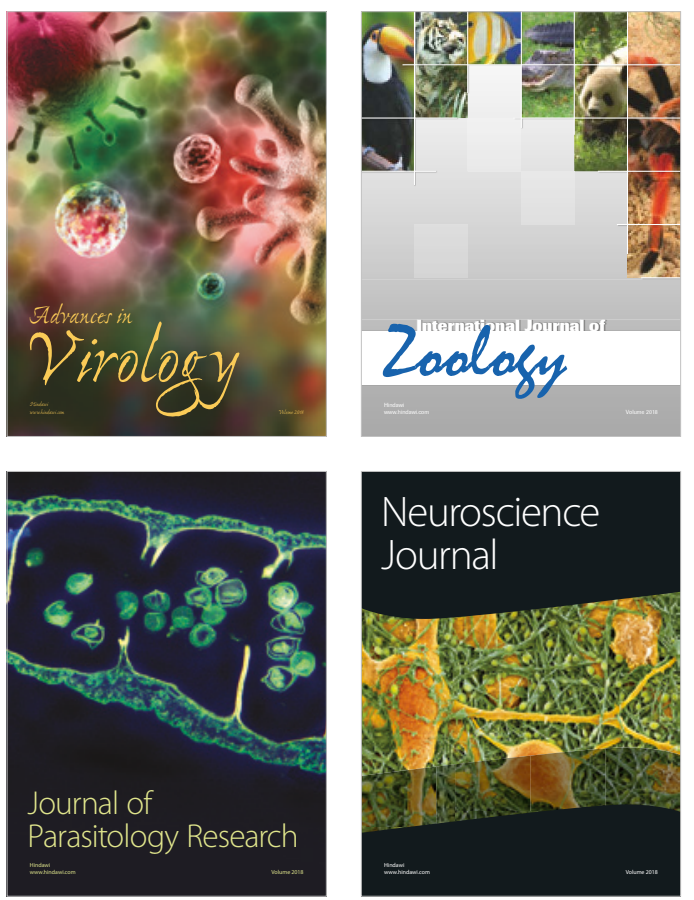
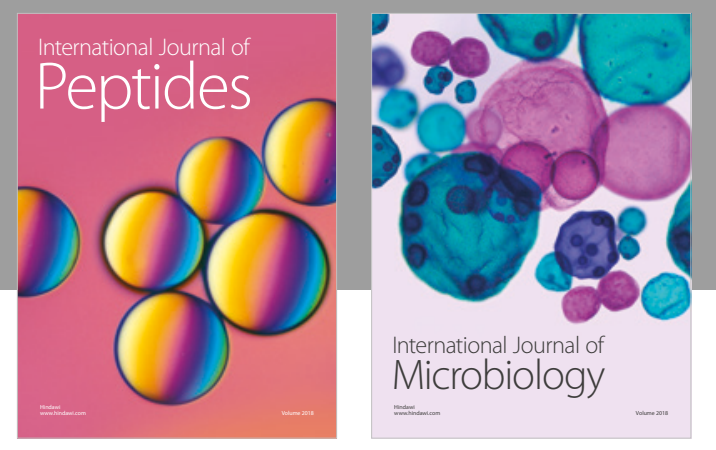

nternational Journal of Microbiology
Journal of
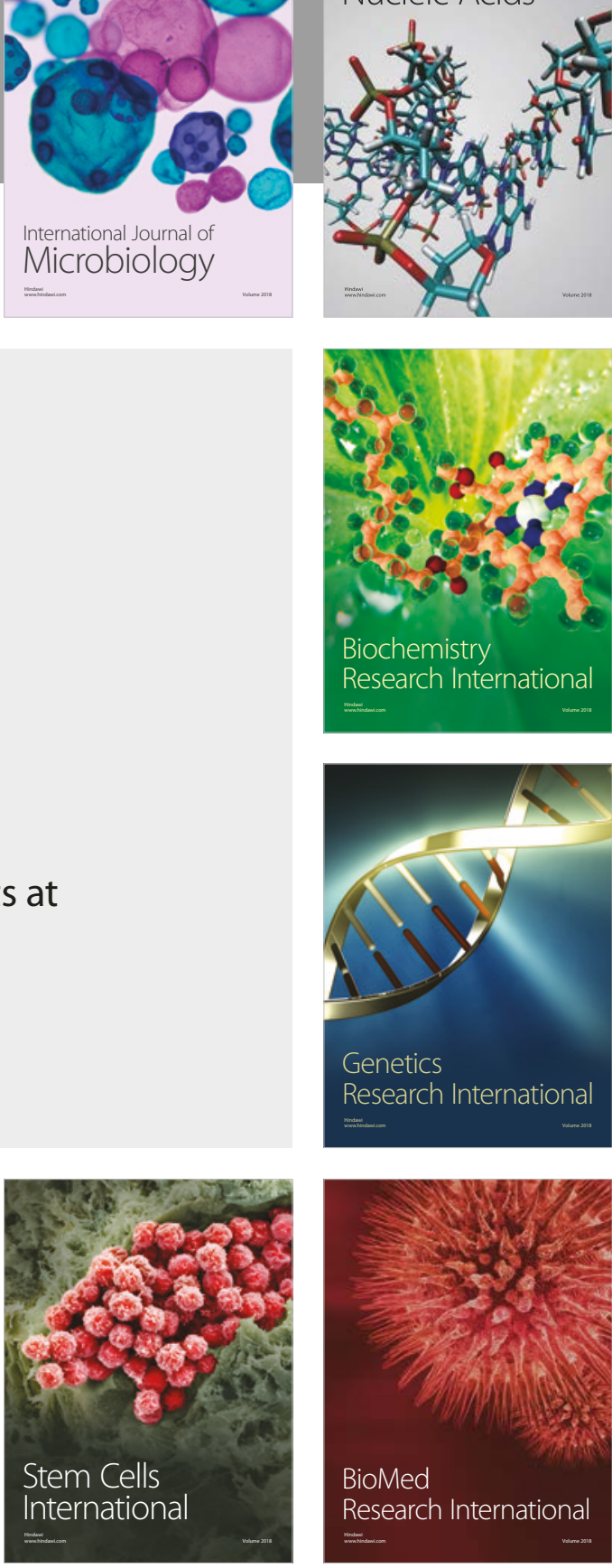
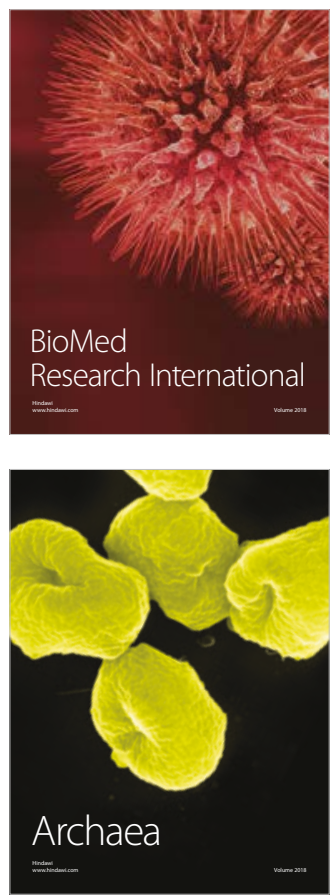